


\section{RAISING P. V. SQUABS FOR PROFIT}

\section{By JOHN S. TREGARTIN}

A Manual of Instruction from My Personal Experience in Building, Stocking and Managing the Largest Successful Squab Plant in New Jersey

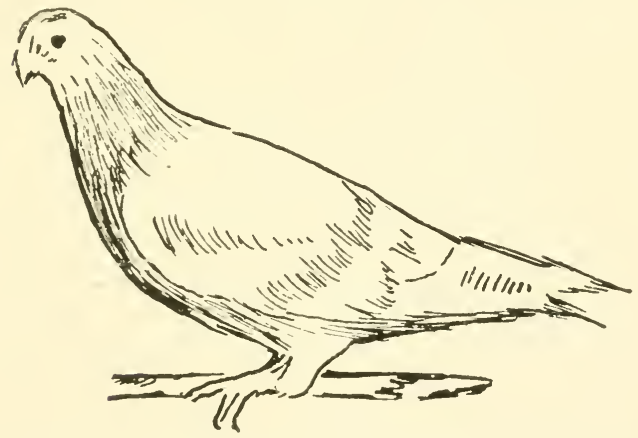

Tells how we market squabs for twelve dollars per dozen, wholesale.

Details of necessary requirements for a successful business.

How to house, feed, market and care for pigeons.

Importance of good foundation stock.

Profits and how secured. 
Introduction .................... 3

Chapter I.

Is There Profit in Raising Squabs?....... 5

Chapter II.

Description of Passaic Valley Squab Farm and

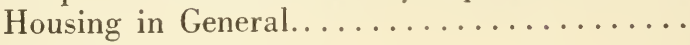

Chapter III.

The Fundamental Requirements for Successful Squab Raising ................. 10

Chapter IV.

The Utility Pigeon................ 17

Chapter V.

Habits and Peculiarities............... 20

Chapter VI.

Squabs for Market................ 24

Chapter VII.

Selecting Breeders................. 28

MAK 10 1920

(C) ClA563916 


\section{INTRODUCTION}

The squab business in America has too long been looked upon as a pastime and game for children's amusement. Raising squabs is not child's play, but a real scientific business with unlimited possibilities for development.

Success in this business as in any other, depends largely on a proper start. In the following pages I will endeavor to present with great simplicity the right way to start in the squab business and the results I have obtained in raising squabs for market. The information contained herein, may, I trust, be of as much benefit to the reader as it is my pleasure to impart.

\section{JOHN S. TRECARTIN.}




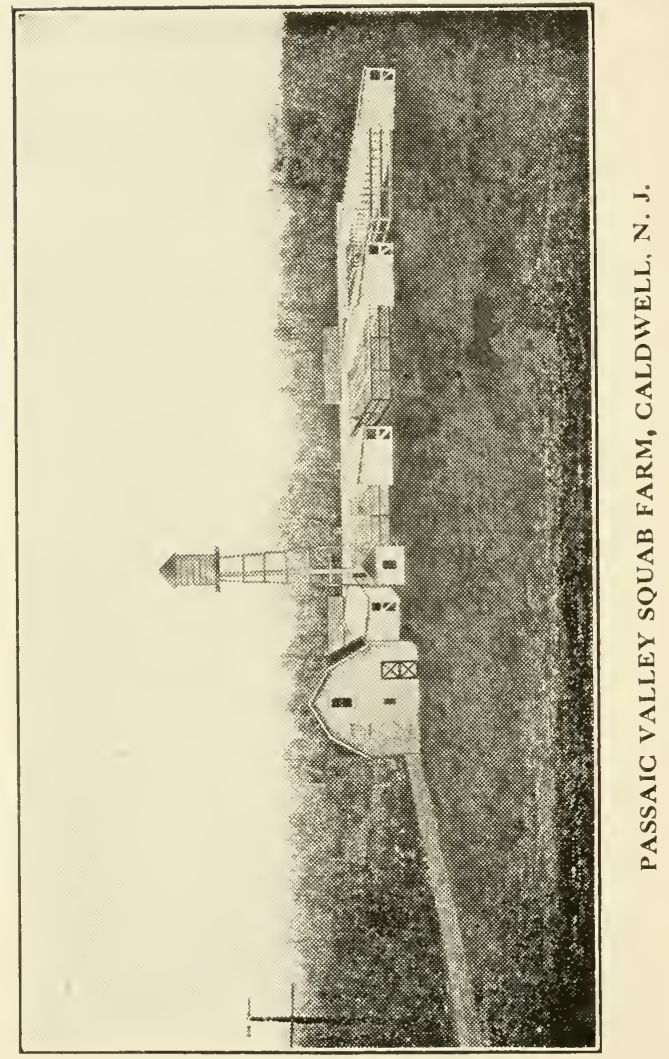




\section{CHAPTER I.}

\section{IS THERE PROFIT IN RAISING SQUABS?}

Of the question of profit in squab raising, there is no doubt. Squabs are coming into use more and more every day, not only as a delicacy for invalids, but also for hotels, restaurants, catering establishments, and household use.

The first question is naturally of the market for them. The Hebrews, who entertain lavishly, are among our largest customers. They buy the squabs alive, as their poultry has to be prepared according to the Jewish Dietary Laws. The hotels in all large cities use enormous quantities of squabs, and we have had to freeze large quantities for them in the summer in the past few years, so as to insure them a steady supply through the winter months. We have frozen as high as 5,000 squabs for a single hotel in one year, and now we make a practice of always keeping a reserve of frozen squabs, to meet the winter demands.

The prices of squabs are for the most part regulated by the large cities in the vicinity. Commission merchants are always anxious to buy in any quantity and they send out weekly quotations as to what they are paying for squabs. The prices to butchers, hotels, and consumers of all classes, are based on these quotations and naturally the direct sale to the consumer, cutting out the commission man, commands a much higher price. 
The following table is made up of the quotations Conron Bros., New York City, paid for squabs during the first week in January in the following years:-

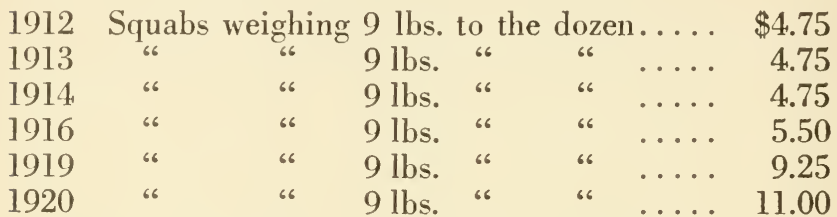

Squabs are graded according to the weight of one dozen. That is, one dozen squabs weighing twelve ounces each, would weigh nine pounds to the dozen. We have taken that weight squab as a basis, as that is the average weight squab produced from good breeders.

The cost of raising squabs depends entirely on the price of feed and the number of squabs produced during a given period. Before the war, it cost $\$ 1.25$ a year for feed for one pair of pigeons. At present, the cost per pair for feed is $\$ 3.00$, according to our records. Now, how many squabs will a pair of pigeons produce in a year? That question we cannot answer, but we know how many squabs we have produced from our breeders. In 1919, we raised an average of 14.3 squabs per pair, for our entire plant. Our average pen production ran from 10 to 16 squabs per pair a year, and as we always select our breeders for their fast breeding qualities and plump squab, we fully expect to average 15 squabs per pair in 1920. 
Considering the useful breeding life of a pigeon, which continues for five years, the question of profit in raising squabs should answer itself.

The selecting of breeders will be treated in full, further in the book.

\section{CHAPTER II.}

DESCRIPTION OF PASSAIC VALLEY SQUAB FARM AND HOUSING IN GENERAL.

The Passaic Valley Squab Farm, I feel, is an ideal plant in an ideal location. It embodies all the best points and has few detriments.

I am going to describe it rather carefully, pointing out its advantages and how it might be improved upon. The diagram will give a general idea of the floor plan, and photo in beginning of book gives a view of entire plant and water tower.

The plant is situated in a valley, protected from the full sweep of the wind. The buildings cover about one acre of land and consist of 86 pens combined into one large connecting building. (A) is granary and stock house. (B) is picking and packing room. (C) is office. The granary has entrance to sections $1,2,3$ and 4 , by halls. Each section is divided into 20 pens, each 10 feet by 12 feet, with entrance on hall. Each pen has its own aviary, 10 feet by 20 feet, for the pigeons to exercise. 
The pigeons nest and raise their young inside, but bathe and exercise outside, where they have running water. Each pen accommodates 50 pairs of pigeons, so the plant capacity is over 8,000 birds.

Water is supplied by an artesian well and electric driven pump, that pumps to tower shown in picture. Each section is watered by one pipe rumning full length of building and perforated at each pen. The pan at each pen fills and when full runs down an overflow pipe into a drain under building. In this way a whole section of 20 pens is watered with one shut-off and the supply is always fresh. All pipes in this system slope to one low point, so that even in zero weather, we can water and drain the pipes without difficulty. The bathing system is worked on the same plan in the aviaries, but we disconnect this part of the system in the extreme weather.

The entire plant is raised about 18 inches off the ground at all points, as a protection against rats. All entrances have heavy screen doors as well as wooden ones, which work with weights to always keep them shut. In this way, rats are kept out, and any pigeons which may get loose inside the halls, are always caught. Rats are the greatest menace to successful squab raising and too great precautions cannot be taken. 


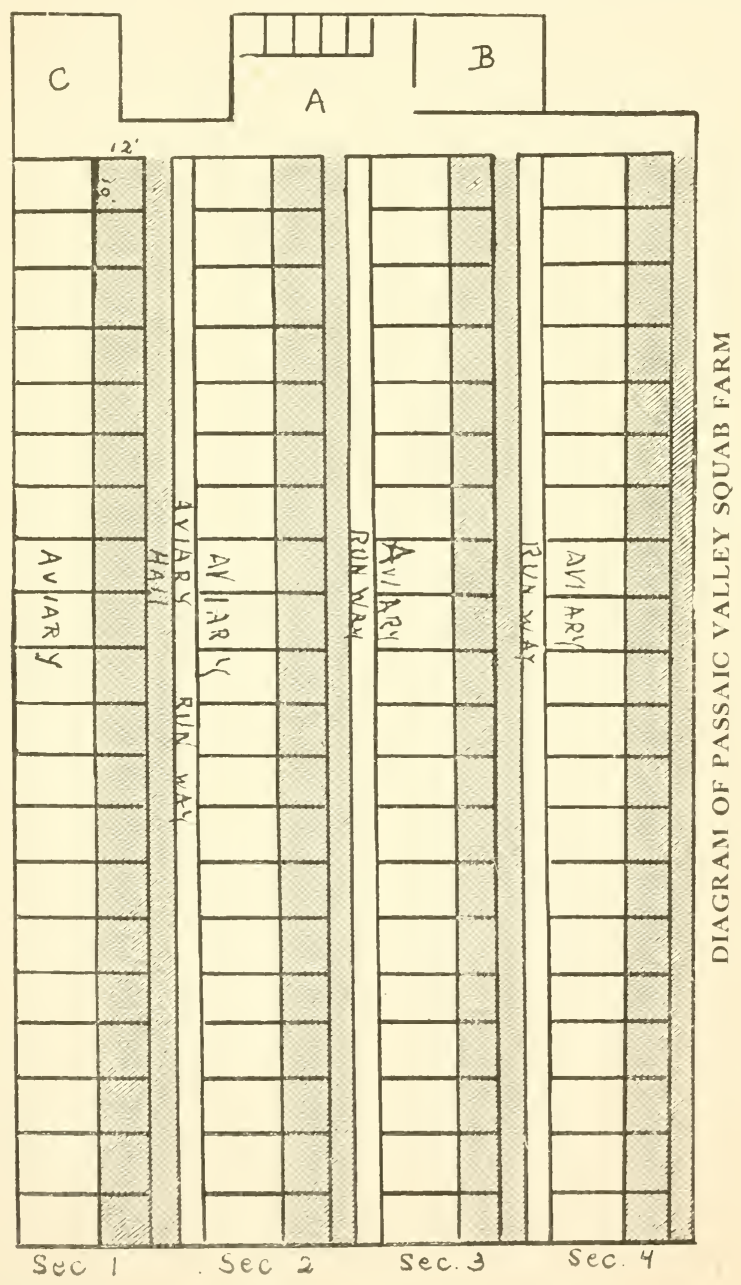


You will note on looking over diagram of plant that sections 1,2, 3 and 4 are connected by granary only. This feature could be considerably improved by a hall connecting the four sections at the other end. Then again, there are no windows on the north side of all four sections, and although this was done to keep out cold, it could be improved with a few windows for greater light.

Altogether I feel that the plant is as near to a model plant as can be found, and being within 20 miles of New York City and eight miles of Newark, the best markets are always available.

I am not describing this plant to discourage any one starting in a small way in a back yard, barn, or outhouse; but I wish to show the possibilities within the grasp of any one to establish a real profitable business of his own.

In the next chapter, I will handle the situation from the beginner's standpoint.

\section{CHAPTER III.}

\section{THE FUNDAMENTAL REQUIREMENTS FOR SUCCESSFUL SQUAB RAISING.}

Good squabs can be raised in any structure, free from dampness, that has sunlight and can be protected from rats. Any shed, outbuilding, or chicken coop can be turned into a first-class pigeon pen with little difficulty. First, the building must be made habitable by patching 
all cracks and leaks in roof. If the locality is subject to cold wind, snow and ice, attention must be given to sides and floors. The floors, particuarly, should have no holes, and double floors are a decided asset for the northern breeder.

Making the house rat-proof, is very important, and the best method I know is to raise the building on posts, not less than 15 inches from the ground at all points. Line the posts with tin or put a can over the top, as is done with corn cribs, and you will be well protected. A window must now be put in the southern side of house to allow the pigeons to reach the flying pen or aviary. The door also must be tight, and it is safest to have a screen door on the inside, with a spring to always keep it in place. If this is lined with one-half-inch mesh wire, it will serve as a protection from rats, and allow for good ventilation.

Equipping the house is easily and cheaply accomplished by the use of egg crates turned on the side, with opening facing out. These should have a three-inch strip nailed across front at bottom of crate, to keep the squabs and eggs from falling out, or better still, make an inside rectangle of three-inch lumber that just fits inside the crate. By this, I mean a draw three inches high and eleven and one-half inches in width and length, but without a bottom, as the lower side of the crate completes the bottom. 

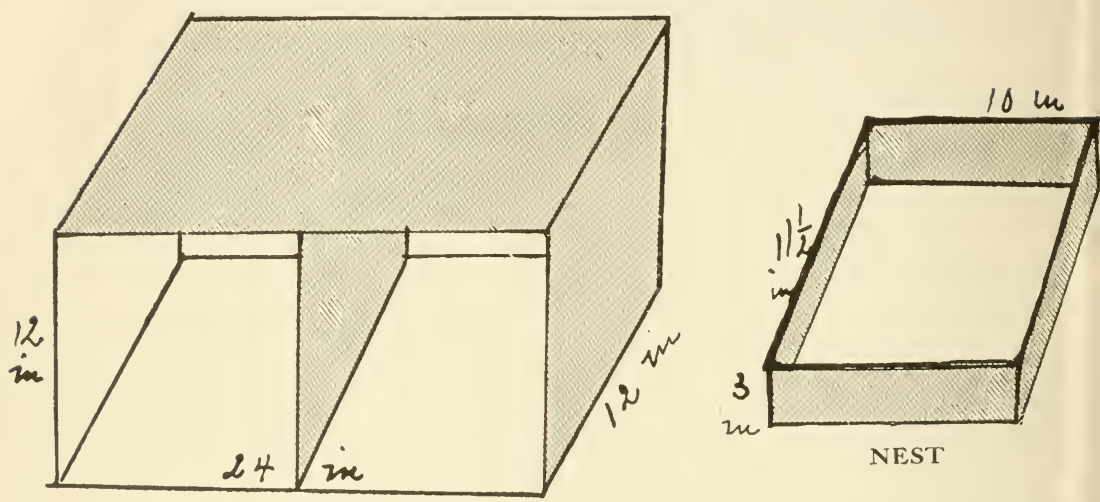

FRONT OF CRATE

Figure 3. CRATE IN POSITION AND NEST

With this draw in place, the squabs are protected with a three-inch partition in front, and to clean, simply pull the draw out and have a basket beneath to catch the nest in. In making the so-called draw, care should be taken to cut two pieces eleven-and-one-half inches and two tenand-one-half inches. The eleven-and-one-half-inch pieces are to run all the way to the rear of box, and the shorter pieces comprise the front and rear pieces. The longer pieces overlap the front and rear pieces and are nailed securely. By having the front and rear pieces short and the side pieces long, the draw will always pull out without breaking. If made the other way, the nails may pull out when you clean house. The ten-and-one-half-inch 
pieces are figured on the basis of using lumber that is five-eighths-inch in thickness. Figure No. 3 shows crate in position and nest ready to put in place.

One pair of pigeons uses both sides of one egg crate as they like to alternate in breeding. Sometimes they have squabs in one side and commence a nest in the other side. By the time the squabs are three weeks' old, there will often be eggs in the other side of box. After crates and nests are ready, arrange in east and west side of per, piling as high as necessary to accommodate the number of pairs. The north side of house may also be used for nest boxes, or, if the east and west sides of house are piled near the roof, it is well to have a landing board or perch on the north end. A shelf should always be put above the southern window and two openings cut through the side, to let the birds into the aviary, when the window is closed.

Outside, there must also be a corresponding shelf for the pigeons. One hole is not sufficient, as a cock bird will often block the one opening and keep other birds off their eggs until they are chilled. To complete the inside equipment, you need a drinking fountain or pan, so protected that the pigeons can only put their heads into the water. A small box will do for grit and this should be placed near the floor in a clean spot, protected from all droppings. The feed, I believe, is best handled by spreading in a long, narrow trough about one-and-one. 


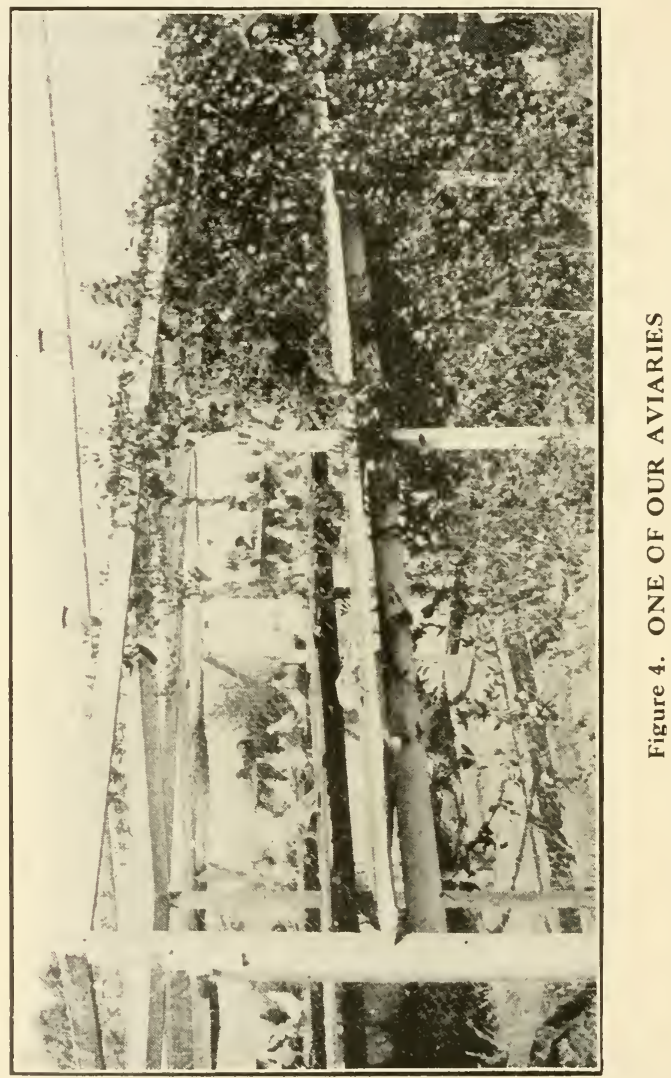


half inches high and long enough so that all the pigeons can get a chance at the food at the same time. In a pen of 50 pairs, this is not practical, but I have the trough six feet long, ten inches wide, and two inches deep, for a large number like this.

The aviaries, except for being on the southern side of building, can vary according to available space and num. ber of birds. Pigeons, for best results in housing, should never be crowded into less than one square foot to a bird and one-and-one-half or two square feet is best. The aviaries should have two to three square feet to a bird and should be from six to ten feet in height. Our pens are 10 by 12 feet inside and 10 by 20 by 10 outside. These pens accommodate 40 to 50 pairs comfortably. Two-inch mesh wire is all that is required, although some breeders use one-inch mesh. In ordering wire, specify galvanized after weaving, or galvanized before and after. It pays to do this, as good wire lasts eight or nine years. The posts or uprights for aviary should be two by four lumber with the sunken end well tarred, or any fairly heavy posts available. If the fly is to accommodate more than five or ten pairs of pigeons, nothing smaller than two by four should be used in the frame work, provided that the winters are severe. A heavy snow will some. times hold on the wire, and is apt to break the supports and release the birds. Particularly watch the fastening of your wire to the coop along the top edge. 
The outside equipment consists of a bathing pan about 24 to 36 inches in diameter and four to six inches in depth. A door should be provided in aviary and a few perches or landing boards, along the sides.

This, I believe, completes the necessary house to make a successful start, and the only exceptions I would make are for the breeders in warm climates, who can best be advised to follow the example of neighboring chicken and pigeon raisers. In southern California, I saw fine squabs raised with a northeastern exposure, no floors, and only a three-sided shed. Here one side was open entirely and nest boxes were built high enough to protect from rats. The aviaries were constructed of slats instead of wire, so as to furnish greater protection. In Jacksonville, Fla., I went through a large plant very similar in construction to the northern breeders, and the feeding was about the same as mine. Each locality has a few distinguishing features, so if you combine these instructions with a little observation and thought, you cannot go far wrong as to proper housing.

In the next chapter I will deal with the breeders, and it cannot too often be said, that no matter how fine the plant and equipment, it will all be wasted unless you start with foundation stock, that has been scientifically perfected. 


\section{CHAPTER IV. \\ THE UTILITY PIGEON.}

From my experience in true utility breeding, or squab breeding for market, there is one basic bird that stands for hardy, plump, even-sized squabs, and plenty of them. That bird is the homing pigeon. The homer will breed more squabs in a year and use less feed, per pair, a year, than any bird I have ever handled. The birds are very hardy, can stand extreme cold and breed well through the winter months. Unfortunately, even these birds have a slight failing. The true homer breeds a squab a little small for the best market price. The squabs run six, seven and eight pounds to the dozen, and the best demand is for eight, nine and ten pounds to the dozen squabs. We experimented carefully with many of the larger breed of birds, but they all had a failing, some would breed well in summer, but not in winter; some ate too much for the number of squabs produced; some would breed one large squab and the other very thin; and some would breed nice twelve-pound squabs, but we could not get a proportionately high price for them to warrant the extra food required and extra time required for them to mature. After seven years of experimenting, we believe we have now the best utility bird in the country, namely the P. V. Special Homer. These birds breed squabs the marketable size: eight, nine and ten pounds to the dozen. Less than 15 per cent. ran 
under eight pounds to the dozen last year. They breed plump, broad-breasted squabs and do not eat more than the average homer. The squabs are ready for market in four weeks from the time hatched, and if kept for breeding, they commence mating in three months; being one of the quickest birds to mature.

A small start with good birds is the foundation of success. A fine flock can be built up from a few good pairs, but poor stock will soon discourage anyone and do harm to the business.

Next to P. V. Homers, we believe the P. V. Carneaux are the best. These birds breed a nine, ten, eleven and Iwelve pound to the dozen squab, and always a beautifully-shaped and white-meated squab. Of course, these fine, large birds will eat more than homers and the squabs will take a little longer to mature, but if you are in a locality to command a high price or sell them retail, you cannot go wrong in having a few pairs. These birds are particularly tame and can easily be made into pets.

I believe firmly, that for profitable squab raising these two breeds of pigeons are decidedly the best choice, although there are other good birds for squab raising, such as Mondaines, Royal Whites, White Kings, and Maltese Hen Pigeons.

We have most of these birds for show purposes, but we will not go into detail, as we feel that P. V. Homers and Carneaux are really the best utility breeders. 
A word of caution might well be put in here against buying cheap birds. They are never worth any more than you will pay for them, and many are only fit for eating purposes along with common pigeons.

Our method of shipping birds enables them to arrive in first-class condition over very long distances. The birds are packed in strong, light cases with a partition to separate the males and females. A bag of feed and drinking cup go with each case. Instructions are sent with each order for feeding and watering while in transit.

Your attention must now be given to preparing the pen for the pigeons:-

Close all openings into the aviary and see that the drinking pan or fountain is filled with fresh water. Shake a few tobacco stems loosely in a pile under the window or else in a corner. The grit box should be half filled with a good prepared pigeon grit; Red Cross grit is as good as any and contains all the necessary ingredients for the birds. A little feed should now be put in trough. A small handful for each pair, is sufficient at first.

You are now ready to release the birds. The males are marked with a color band on the right leg and the females on the left leg. Keep a record as you let the birds go to see that each male has a female with a corresponding band. That is, a male bird with a blue band 
on the right leg must have a female also with a blue band on the left leg. The next chapter will explain the habits of the birds and why they are banded.

\section{CHAPTER V.}

\section{HABITS AND PECULIARITIES.}

In the first place, pigeons are monogamous. They must always be kept in even pairs, because they select their mate and very seldom ever change, unless forced to select another mate in a mating coop. Even pairs of pigeons will soon settle down quietly in various nest boxes. They usually keep the same nest boxes and alternate, having squabs first in one side and then the other. After the birds have become accustomed to their quarters and have selected in which nest they are going to start housekeeping, it will not be many days, before they begin to carry stems from the pile on the floor and start their nest. They need no assistance and should not be unnecessarily disturbed until they commence laying. This should occur in about two weeks and then it is advisable to look over the nests twice a week, and see that all new nests are well made and do not resemble a golf tee. Birds sometimes will build a high nest and lay the eggs on the top without any support. It is best to spread out a nest of this kind, after removing the eggs, so as to give a good foundation. Make a slight hollow in the 
centre of the stems and then replace the eggs, but be sure and see that the nest is firm enough to keep the eggs from sinking in, under the stems.

It is advisable for the beginner to mark very lightly with pencil, on eggs, the date laid. In this way it is very easy to learn the appearance of an egg at different ages, and soon you will be able to discern a bad egg at a glance and remove it, so that the old birds will not waste time sitting on it. Fresh laid eggs are semi-transparent and have a slightly dull appearance. They gradually grow opaque and solid white, with only an air space discernable unless candled. During the third week, the shell will begin to chip and the baby squab will chip a complete circle, in end of egg and gradually work out. One egg will usually hatch a day in advance of the other. This is accounted for by the fact that there is from one to two days between the time the hen lays the eggs. The birds always lay the eggs in pairs, but once in a while two pairs of birds will lay in the same nest and give the impression that four eggs have been laid.

Bad eggs are discernable easily with a little practice. At a week or ten days' old, bad eggs will have almost the appearance of a fresh laid egg, only they are shiny instead of dull on the outside, and are semi-transparent. If eggs like these are shaken gently, you can feel that they are loose and watery inside. On being held to the light and turned, the air space will shift all over. In 
good eggs, the air space is stationary. An egg, two or three weeks' old, having decided dark lines through it, is a sign that the squab has died in the shell. If uncertain as to an egg, it is best to leave till it developes definite signs of being bad.

Young squabs do not need assistance to get out of shell, but the empty shell can be removed later. The young squabs should not be handled too much and I do not advise any artificial feeding at all, as the old birds will give their young the best care. After eating and drinking, the old birds will fly to the nest and feed the young from their bills, just the right proportions of grain, formed into a substance called pigeon milk. The so-called pigeon milk varies according to the size of squabs and later contains whole grains and water. The squabs should never leave the nest till fully feathered, this takes about four weeks, and at that time the squabs are ready for market. To determine the exact age for marketing, look beneath the wings, as they feather out here last.

The feeding I have not gone into before, as it is contingent on the squabs.

Of course, every locality has peculiarities of its own and certain grains are cheaper in certain places. Your local dealer, no doubt, has a good pigeon feed to start with. Later you can improve and economize by mixing your own feed. 
Our formula for winter feeding, is as follows:Argentine Corn... 30\% Kaffir Corn...... 25\% Red Wheat...... 10\% Buckwheat..... 20\%

$$
\text { Peas .......... 15\% }
$$

Summer feeding is:-

Argentine Corn... 25\% Kaffir Corn...... 30\%

Red Wheat...... 15\% Peas......... 30\%

Using these two formulas as a basis, you can easily arrange the best formula for yourself. Corn and buckwheat are very heatening, and the latter can be entirely dispensed with in warm localities. The corn should either be Argentine Corn or small American Corn with a part cracked corn. The amount of cracked corn is determined by the quality. If you can get a good recleaned steel-cut cracked corn, fairly free from loose fibre, it is all right to use half-and-half with the whole American Corn. Otherwise use $25 \%$ cracked to $75 \%$ whole corn.

All grains must be reasonably cured and dried. Do not buy new crops of grains until well seasoned. Inferior grains like heated corn, or wheat that has sprouted, are all to be avoided. Scratch feed is not to be recommended as a steady diet, but will serve for a while. Most scratch feeds contain rye, barley and oats, all three of which I do not recommend as pigeon feed. Scratch feed also lacks peas, and these are the finest fattening and strengthening food that squabs can get. 
See that the birds get fed regularly twice a day and that they clean up all the food given them, within an hour. The morning feeding should be between 7:30 and 8:30, and in summer, not later than 8 o'clock.

Afternoon feeding should be around 3 o'clock in winter and 4 o'clock in summer. If the birds can only be fed once a day, feed in the morning and see that some feed lasts until 3 o'clock in the afternoon. It is easy to judge by the way the birds fly for the grain whether they are fed too heavily or too lightly.

Fig. 5 illustrates the card we use to regulate feeding.

A circular piece of card board, mounted with a thumb tack through centre, just outside the door, shows how much feed was given at last feeding. The top of card indicates the amount. Always setting the card the amount fed, avoids waste and having too much feed standing around, which may become mouldy and cause sickness.

\section{CHAPTER VI. SQUABS FOR MARKET.}

Squabs are ready for market at from four to four-andone-half weeks from the time hatched. As soon as the squabs are fully feathered, they should be removed from the nest, as they will soon jump from nest and run on the floor, thereby losing weight until killed.

If squabs are to be killed at once, care should be taken to remove from pen just before feeding time, so that their 


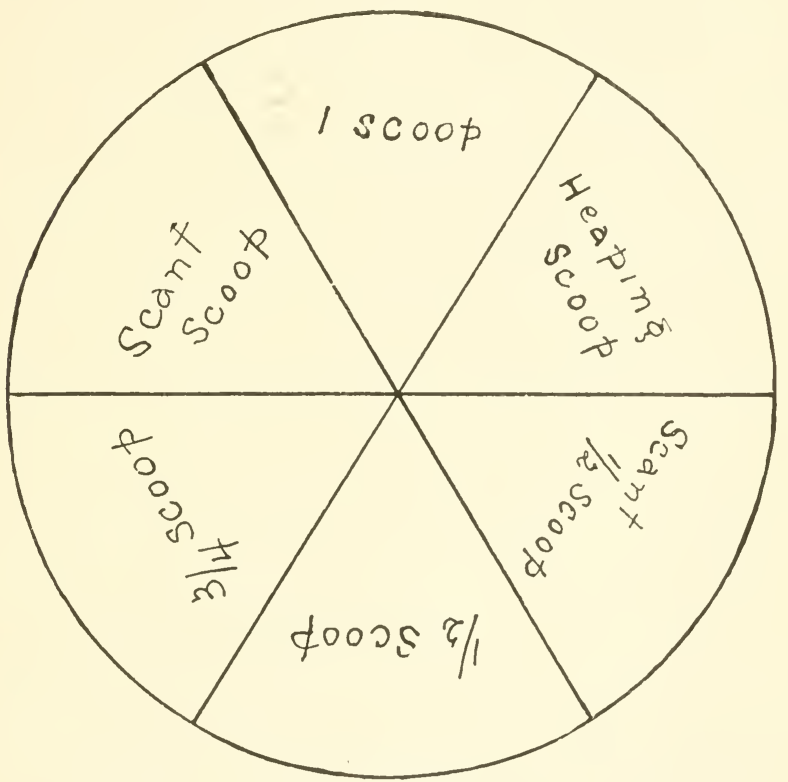

Figure 5. REVOL,VING FEED REGULATOR

crops will not be full of grain. They may even be taken the night before, if kept in a warm place.

To kill squabs properly, they should be hung up by the feet. Two nails driven partially into a board about an eighth of an inch apart will serve nicely to clamp the feet. The wings should now be twisted over each other twice, so that they cannot flap. Killing the squab re- 
quires a little knack. First, take the small blade of a penknife and after grasping the head of the squab firmly with thumb and forefinger, just over eyes, put the blade down the throat at least one inch, and then pull up through the top of head. If squab does not die in thirty seconds, repeat as it is difficult for a novice to cut the wind pipe and brain the first time.

Plucking is easy and should be done while the squab is still warm. Start with the wings, which are the hardest, and end with the tail feathers. Picking against the feathers is quickest and is less likely to tear the skin.

After picking, the squab should be dropped into cold water to cool and harden. It is best for them to soak for at least three hours, and over night will not harm them, if the water is cold and something is put over top so as to keep squabs entirely below the surface.

Grading squabs as to size depends on whom you are selling to. Small, medium, and large, is usually sufficient grading, but if you desire to grade by pounds to the dozen accurately, the following table shows just what grade various weight squabs come under.

\begin{tabular}{|c|c|c|c|c|}
\hline Poul & $\mathrm{tl}$ & loze & quabs & 8 ozs. to $91 / 3$ ozs. \\
\hline “ & "6 & “ & "“ & $91 / 3$ ozs. to $102 / 3$ ozs. \\
\hline “ & ، & “ & “" & $102 / 3$ ozs. to 12 ozs. \\
\hline " & " & . & "• & 12 ozs. to $131 / 3$ ozs. \\
\hline " & “" & “ & " & $131 / 3$ ozs. to $14 \frac{2}{3}$ ozs. \\
\hline “ & “6 & “6 & “" & $142 / 3$ ozs. to 16 ozs. \\
\hline "6 & 66 & 66 & "“ & over 16 ozs. \\
\hline
\end{tabular}


It is not necessary to weigh each squab individually. A half-dozen about the same size will show the approx. imate weight per dozen.

In packing squabs to ship by express, they should be laid side by side or feet up and tight enough so as not to shake around. In warm seasons ice should be used between each layer and newspapers will help to hold cold and avoid bruising. Mark every shipment "PERISHABLE -Rush," and always send an invoice in all shipments sent to commission merchants.

In sending squabs alive, care must be taken to get the birds out with full crops, so that they will not loose weight in transit. The crate for shipment should be fairly open to allow for plenty of ventilation. Overcrowding must be avoided as the squabs huddle in groups and smother easily. A regular spindle coop, about 24 inches by 36 inches and 1 foot high, will hold 30 live squabs for shipping; more than that is risky.

All shipments of live squabs should also be marked, "Perishable-Rush," the number of birds in shipment, and also the value.

If squabs are to be sold for breeding purposes, they should not be shipped till they are at least eight weeks' old, and preferably ten weeks. Only strong birds should be shipped and no shipments should be made in extremely cold weather. 


\section{CHAPTER VII. \\ SELECTING BREEDERS.}

Selecting squabs for breeding purposes must be done with great care and understanding. If the right kind of birds are not selected your flock will gradually deteriorate. With careful selection, although slow, you will consantly be adding profitable breeders to your stock. This is, of course, if you start with P. V. Breeders, so as to have the neucleus of a good flock to start with. Remember, good breeders will breed plump, white squabs at a fast rate, while poor breeders will grow small, dark squabs that have not the vitality to ever be first-class breeders. Even with P. V. breeders you must use care in selecting the young, and it is wise when starting with a few of our breeders to sell your squabs for a time and buy more of our breeders until your flock is large enough to have a good selection to choose from.

The months when squabs should be saved for breeders are, February, March, April and May. The birds are in the best of condition then and the squabs will be strong and vigorous. June and July squabs are good, but are more expensive to raise, as they are at mating age in September, October and November, when they are subject to moult and are difficult to mate at this time. I do not recommend saving squabs during the other months, as I have found from experience that they will breed well 


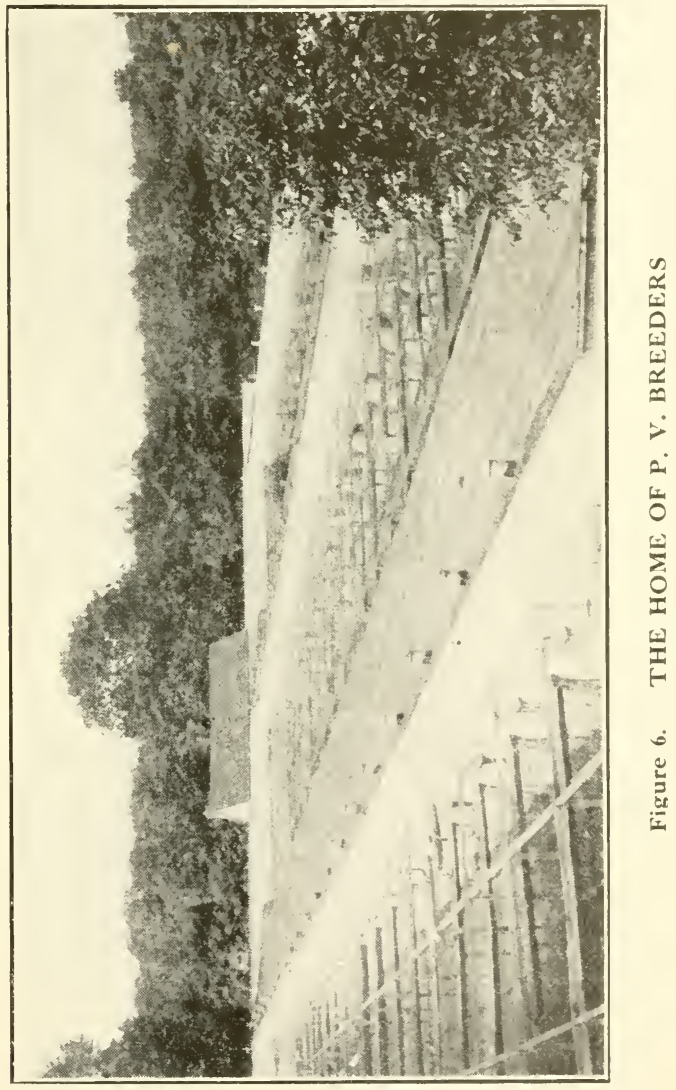


for two or three years, and then, there is a falling off in squabs and a heavy death rate among the hens.

When ready to select your squabs for breeders, get some light pigeon bands. We use a celluloid coil band that wraps around the leg and stays in position without fastening. By using a different color band every month, we know at a glance the age of the youngster. Always take your squabs in pairs and unless there are two good healthy squabs in the nest do not take them. They do not have to be of unusual size, but they should both be well fed and weigh eight, nine or ten pounds to the dozen if dressed. Band one bird on the right leg and the other on the left and put back in the nest again. This banding is merely to keep from inbreeding and marking so as not to kill, and has nothing to do with their being males or females. It is impossible to tell with certainly the sex of a pigeon without noting its actions. With squabs it is still harder, and although after becoming experienced, it is possible to make accurate guesses, one is apt to make a mistake evcn with old birds.

The squabs banded should be left with the parent birds till they are eight weeks' old. Then remove to separate pens. The birds banded on the right leg should go in one pen and the youngsters banded on the left leg in a separate pen. This will prevent nest mates going together and avoid inbreeding. 
The feeding and care for these birds should be the same as for old breeders, except that they should not have large American Corn and only five per cent. peas. The grit should have a little olive oil mixed with it once a week. The birds will thrive satisfactorily for about one month in their new quarters and then care has to be taken to see that they do not get out in rainy weather, as they undergo a moult and are very subject to cold. This moulting time lasts for about three weeks, and when they get past this stage you will see signs of the birds mating. Do not be in any hurry to mate them, as their first eggs are usually bad and they sometimes will break their matings when taken out too young.

The safest way to mate young pigeons is to catch the birds sitting on eggs. Color band the hen on the left leg, who usually sits in the morning till around 11 o'clock. The corresponding band should be fastened somewhere on the nest, and when you see the mate sitting on the eggs, in the afternoon, you must catch him, and band on the right leg. Catching pigeons is usually done with a landing net or crab net with a short handle. The birds should always be caught from behind, if flying, so as not to injure them. After you have caught the pair, they should be removed to a separate pen so that they can start to breed without interference. If the eggs are good that they were sitting on, they can be placed under other birds that have eggs of about the same age, and some- 
times are raised satisfactorily. Do not make the mistake of just leaving all your youngsters alone and trusting they will form even pairs, for if you do, there are sure to be odd cocks that will interfere seriously with their breeding.

Night mating with a flash light is the quickest method, but requires a dark night and considerable skill to always pick out the mated pairs. Mated pairs will often sit together on the front of their nest at night or the hen on the eggs or squabs and the cock on the front. These birds can be readily caught but great care must be exercised lest the other birds fly off their nests and spoil their eggs.

Driving pairs, that is, when one bird continually chases another around pecking at it, are usually mated but not always, so be careful to watch them closely if you select mated pairs this way.

As a closing remark I would say, I have found raising squabs is one of the pleasantest, most interesting, and profitable ways of employing spare time, and whether you are a man or woman, if you apply this motto, you can succeed in the squab industry.

Good Breeders, Good Feed, and Good Care, Then You Will Get

Good Squabs, Good Prices, and Good Profits, Namely, SUCCESS. 



\section{LIBRARY OF CONGRESS}

||||| || || |||||||||||||| ||||||||||||

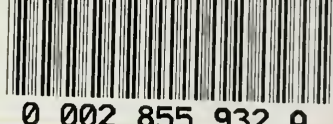

$0002855932 \mathrm{~A}$ 